\title{
Ecological pathways to prevention: How does the SASA! community mobilisation model work to prevent physical intimate partner violence against women?
}

Tanya Abramsky ${ }^{1 *}$, Karen M. Devries ${ }^{1}$, Lori Michau², Janet Nakuti², Tina Musuya ${ }^{3}$, Ligia Kiss ${ }^{1}$, Nambusi Kyegombe ${ }^{1}$ and Charlotte Watts ${ }^{1}$

\begin{abstract}
Background: Intimate partner violence (IPV) against women is a global public health concern. While communitylevel gender norms and attitudes to IPV are recognised drivers of IPV risk, there is little evidence on how interventions might tackle these drivers to prevent IPV at the community-level. This secondary analysis of data from the SASA! study explores the pathways through which SASA!, a community mobilisation intervention to prevent violence against women, achieved community-wide reductions in physical IPV.

Methods: From 2007 to 2012 a cluster randomised controlled trial (CRT) was conducted in eight communities in Kampala, Uganda. Cross-sectional surveys of a random sample of community members, aged 18-49, were undertaken at baseline $(n=1583)$ and 4 years post intervention implementation $(n=2532)$. We used cluster-level intention to treat analysis to estimate SASA!'s community-level impact on women's past year experience of physical IPV and men's past year perpetration of IPV. The mediating roles of community-, relationship- and individual-level factors in intervention effect on past year physical IPV experience (women)/perpetration (men) were explored using modified Poisson regression models.
\end{abstract}

Results: SASA! was associated with reductions in women's past year experience of physical IPV $(0.48,95 \% \mathrm{Cl}$ 0.16-1.39), as well as men's perpetration of IPV $(0.39,95 \% \mathrm{Cl} 0.20-0.73)$. Community-level normative attitudes were the most important mediators of intervention impact on physical IPV risk, with norms around the acceptability of IPV explaining $70 \%$ of the intervention effect on women's experience of IPV and $95 \%$ of the effect on men's perpetration. The strongest relationship-level mediators were men's reduced suspicion of partner infidelity (explaining $22 \%$ of effect on men's perpetration), and improved communication around sex (explaining $16 \%$ of effect on women's experience). Reduced acceptability of IPV among men was the most important individual-level mediator (explaining $42 \%$ of effect on men's perpetration).

Conclusions: These results highlight the important role of community-level norm-change in achieving community-wide reductions in IPV risk. They lend strong support for the more widespread adoption of community-level approaches to preventing violence.

Trial registration: ClinicalTrials.gov, NCT00790959. Registered 13th November 2008.

The study protocol is available at: http://www.trialsjournal.com/content/13/1/96

Keywords: Violence prevention, Impact evaluation, Community mobilisation, Intimate partner violence, Uganda, Pathways analysis, Gender based violence, East Africa

\footnotetext{
* Correspondence: tanya.abramsky@lshtm.ac.uk

${ }^{1}$ Gender Violence and Health Centre, London School of Hygiene and Tropical

Medicine, 15-17 Tavistock Place, London WC1H 9SH, UK

Full list of author information is available at the end of the article
} 


\section{Background}

Violence against women is widely recognised as a serious human rights and public health concern, one that is associated with a range of poor health outcomes including HIV infection [1-4]. Intimate partner violence (IPV) is the most common form of violence against women, with recent estimates suggesting that $30 \%$ of ever partnered women worldwide will experience physical and/or sexual violence by an intimate partner during their lifetime [5].

Ecological frameworks are now extensively used to describe the multiple levels (societal, community, relationship, individual) at which factors operate to influence IPV risk [6, 7], and there is growing recognition that as well as targeting individuals, violence prevention strategies must address the social, cultural and economic contexts in which IPV occurs. Community- and societallevel factors shown empirically to be linked to women's risk of experiencing or men's risk of perpetrating IPV include norms relating to the acceptability of wife beating [8-12] and male authority over female behaviour [9], norms granting men economic and decision-making power in the household [13], low levels of autonomy among women [14], lack of easy access to divorce for women [13], low literacy rates [15], low levels of female education $[9,11]$, high levels of poverty and unemployment [16], and lack of community sanctions against IPV [17]. These contexts in turn engender many of the individual- and relationship-level factors associated with increased risk of IPV, such as childhood experience of abuse or exposure to violence between parents, attitudes accepting of violence against women, low levels of education, harmful use of alcohol or drugs, economic stress, conflict or dissatisfaction in a relationship, male dominance in the family, and men having multiple partners [7, 18-20]. And yet, to date, there is little evidence on how interventions might engage with community-level drivers of IPV-risk in order to achieve community-wide reductions in violence.

Extant IPV prevention interventions which have sought to challenge regressive gender norms or address women's economic dependence on men, have often comprised small group based workshops, sometimes coupled with livelihood strategies. They have for the most part targeted enrolled individuals, and - while they have met with success in changing attitudes, relationship dynamics and behaviours among group attendees - their impacts on norms within the wider community have not been evaluated [21-24].

Community-level approaches commonly used to try and change norms include awareness raising campaigns, such as the annual 16 Days of Activism against Gender Violence, which though helpful in bringing discussions of violence out into the open and providing a focus for local action, rarely have sufficient intensity or theoretical grounding to transform norms or change behaviours [7]. 'Edutainment' programmes such as Soul City in South
Africa and Sexto Sentido in Nicaragua [25, 26] - that use media and/or entertainment to reinforce social change messages at a community level - are also an increasingly popular approach to changing norms and behaviours. Such programmes arguably offer the greatest potential for change when used as part of broader community mobilisation strategies, which use diverse strategies to reach and engage as many people as possible [21]. Because the design, implementation and evaluation of such interventions are so complex, however, there is scant evidence on their potential effectiveness and the mechanisms through which they might work [21].

We recently reported the results of the SASA! Study, a cluster randomised controlled trial to assess the community level impacts of SASA!, a community mobilisation intervention to prevent violence against women and reduce HIV-risk behaviours in Kampala, Uganda [27]. After just under three years of intervention programming, women in intervention communities were $52 \%$ less likely to report past year experience of physical IPV, compared to women in control communities (adjusted risk ratio 0.48, $95 \%$ CI 0.16-1.39), and also somewhat less likely to report past year experience of sexual IPV (aRR 0.76, 0.331.72). Though an increase in inter-community variation in prevalence of these outcomes over the course of the study reduced study power to obtain statistically significant results in relation to IPV, large effect sizes and consistency in direction of effect between these, other primary outcomes and secondary violence outcomes are strongly suggestive of an intervention effect on levels of IPV. The study also found statistically significant impacts on male and female attitudes towards the acceptability of IPV, and reductions in past year sexual concurrency among men [27]. This was the first trial in sub-Saharan Africa, shortly followed by a second study from Uganda [28], to show community-level impacts on IPV-related attitudes and behaviours, with the effects not confined to individuals reporting direct exposure to the intervention - effect sizes were similar whether the analysis was restricted to explore effect among individuals reporting above a threshold level of exposure to the intervention, or done on an Intention to Treat (ITT) basis whereby all members of intervention communities (both exposed and unexposed) were included [27].

Having demonstrated that community level change is possible, this paper explores the potential pathways changes in individual-, relationship- and community-level attitudes and behaviours - through which reductions in IPV were achieved in the SASA! study communities.

\section{Methods}

Study setting

The SASA! Study was conducted between November 2007 and May 2012 in the Rubaga and Makindye 
Divisions of Kampala, Uganda. Uganda has a high prevalence of IPV and HIV/AIDS, and patriarchal norms are a dominant aspect of the sociocultural environment. In Kampala, $9.5 \%$ of women aged $15-49$ are estimated to be living with HIV [29], and $45 \%$ of ever-married women aged 15-49 report having experienced physical and/or sexual violence by an intimate partner at some point in their lives [30].

\section{The SASA! intervention}

The SASA! Activist Kit for Preventing Violence against Women and HIV [31] is a community mobilisation intervention seeking to change community attitudes, norms and behaviours that result in gender inequality, violence and increased HIV vulnerability for women. A central focus of the intervention is to promote a critical analysis and discussion of power and power inequalities - not only the ways in which men and women may misuse power and the consequences of this for their relationships and communities, but also how people can use their power positively, to affect and sustain change at an individual and community level. SASA! was designed by Raising Voices (http://raisingvoices.org/) and implemented in Kampala by the Centre for Domestic Violence Prevention (CEDOVIP) (http://raisingvoices.org/activism/local/).

Designed around the Ecological Model of Violence [7], SASA! recognises that IPV results from the complex interplay of factors operating at the individual, relationship, community and societal levels. The approach therefore supports whole communities through a phased process of change, systematically involving a broad range of stakeholders. SASA!, meaning 'Now' in Kiswahili, is an acronym for the four phases of the approach - Start, Awareness, Support, Action (see Fig. 1) - with the phases analogous to the processes set out by Prochaska et al. (1992) in their individual-level behaviour-change Stages of Change Theory [32].

Throughout this process SASA! intervention staff work with four groups of actors: community activists (CAs) selected from among the more progressive men and women rooted in the community, who work voluntarily to facilitate and promote SASA! activities; community leaders including ssengas (traditional marriage counsellors) who, as religious, cultural, governmental and other types of local leaders, are encouraged to integrate ideas of gender and power into their leadership roles; professionals such as health care providers and police officers, who provide direct prevention and response services; and institutional leaders who have the power to implement policy changes within their institutions.

SASA! entails the selection, ongoing training, and mentoring of these individuals and groups, to help improve their knowledge, communication skills, and motivation to participate in mobilising their communities to address gender inequality and violence. They are introduced to, and then supported to introduce into their communities, new concepts of power, encouraging analysis of gender-related imbalances of power through four strategies: Local Activism, Media and Advocacy, Communication Materials, and Training. As part of this, CAs and leaders are supported by CEDOVIP staff to conduct a range of local activism activities, including (but not limited to) public events such as community dramas, discussions and meetings; small group activities; one-onone 'quick chats'; door-to-door discussions; trainings; poster discussions; and film and soap opera shows. Similarly, the police, health workers and other professionals receive training and are supported in efforts to improve the provision of services. In this way, community members are exposed to SASA! ideas repeatedly and in diverse ways within the course of their daily lives, from people they know and trust as well as from more formal sources within their communities. The specifics of intervention activities develop and continually evolve in response to community priorities, needs and characteristics.

In the context of this CRT, eight CAs (four male and four female) were recruited in each intervention parish, and trained and supported to deliver the intervention.
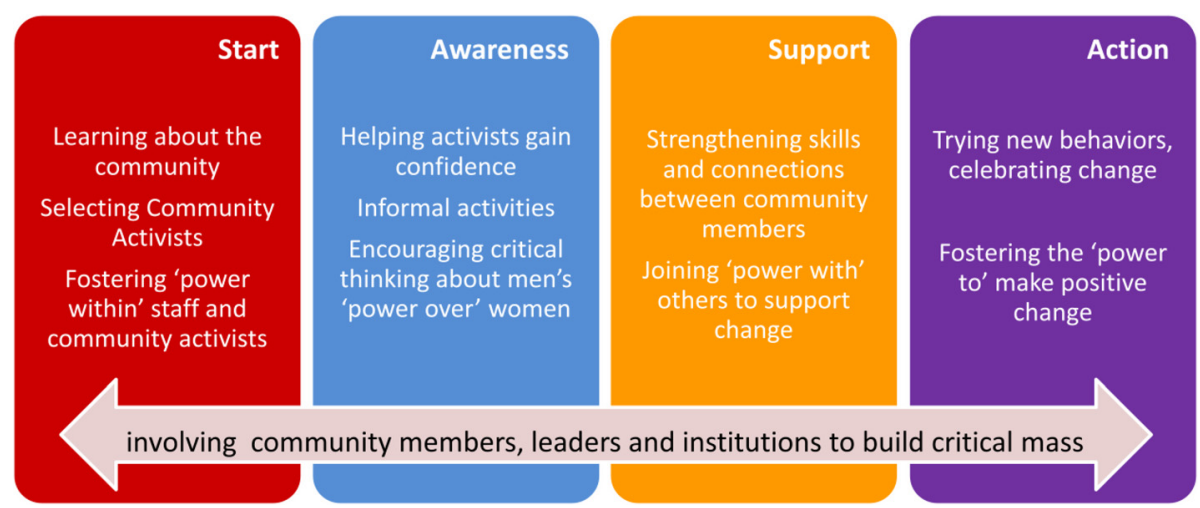

Fig. 14 phases of SASA! 
For sampling purposes (see below for detail) an identical recruitment process was used in control sites, but selected individuals (passive volunteers) went on to receive just one session of basic health education or children's rights training every three months. Programming continued for the duration of the study (equating to approximately 2.8 years of programming after taking into account interruptions caused by political disturbances). Monitoring data show that over the course of the study SASA! activists led more than 11,000 activities, and reached an estimated 260,000 community members (unpublished process and monitoring data).

\section{Trial design}

The cluster randomised trial ran from 2007 to 2012. The design is described in detail elsewhere [33]. Briefly, eight sites (consisting of one or two administrative parishes) were pair matched on the basis of estimated population density and stability/mobility of the population. One from each pair was randomised to receive the intervention, and the other designated as a control.

Two cross-sectional surveys of community members were carried out in all sites, one prior to intervention implementation (baseline) and one approximately four years later (follow-up). The sampling frame for the surveys comprised households situated in the enumeration areas (EA) in which community activists (or 'passive volunteers') lived. For the baseline survey a stratified random sample of 8 community activist EAs per site was selected (64 in total; 32 per intervention arm); at followup, due to increased funding we were able to sample all EAs in which CAs were recruited at the start of the study (96 in total; 48 per intervention arm). 35 households per EA were then randomly selected, and a maximum of one eligible person per household selected to complete the survey. In the interest of respondent safety, to reduce the chance that men in the immediate locality were aware of the nature of the questions in the survey and the potential disclosures that women may make, an exclusively female sample was drawn from EAs in which female community activists lived, and an exclusively male sample drawn around male community activists. Data do not therefore pertain to men and women in the same relationships, nor living in the same immediate localities.

One thousand, five hundred eighty-three respondents were interviewed at baseline and 2,532 at follow-up. Intervention effects on primary outcomes (including women's past year experiences of physical and sexual IPV) were assessed using an adjusted cluster-level intention to treat (ITT) analysis which compared outcomes in intervention and control communities at follow-up [27].

The study received ethical approval from institutional review boards at the London School of Hygiene and Tropical Medicine (UK) (ref.5210), Makerere University
(Uganda) (ref. 2007-101) and the Uganda National Council for Science and Technology (SS 2048). Approval to work in the study communities was obtained from local government offices and leaders, and individual-level written consent was obtained prior to each interview.

\section{Hypothesized pathways to reduced IPV}

The conceptual framework for this analysis (Fig. 2) draws on ecological models of risk factors for IPV, the SASA! Study logic model which laid out a theoretical framework for how SASA! would achieve its long term intended outcomes (Additional file 1) [33], and qualitative research on pathways of change conducted with SASA! community members [34]. Key measurable intermediate outcomes are laid out in an ecological framework, with both primary and secondary prevention of IPV as the central goals. The potential mediators (Table 1) comprise community-level factors (responses to IPV occurring in the community, and normative attitudes towards IPV, women's right to refuse sex or request condom use, and broader gender roles); relationship-level factors (communication between partners, relationship power dynamics, extra-spousal sex partners, relationship dissolution); and individual-level factors for both men and women (drinking behaviour and attitudes relating to IPV, a woman's right to refuse sex and broader gender roles).

Pathways of effect were conceptualised using an ecological framework for the principal reason that SASA! is a community level intervention, and potential pathways of effect may operate at the community, relationship and individual-levels. For example, a woman's IPV risk could decrease because changes in her own attitudes lead her to choose a non-violent partner. However, her IPV risk might also decrease without any antecedent changes in her own attitudes or behaviours, if for example her partner attends intervention activities and becomes less likely to perpetrate IPV against her, or if community change leads others in the community to intervene when they become aware she has experienced IPV. Furthermore, the absence of arrows in ecological models illustrates the interplay of factors operating at different ecological levels - for example, community norm change may affect individuals' behaviours within relationships, which in turn feed back into community norm change.

With a complex community-level intervention such as SASA!, pathways of effect are also likely to vary from person to person, depending on their characteristics, experiences of the intervention, and current situations. For example, pathways that lead to cessation of IPV among women already experiencing violence in their relationship will likely differ markedly from pathways that reduce risk of onset of new IPV among women not previously experiencing violence. Furthermore, multiple pathways of change may operate concurrently within 


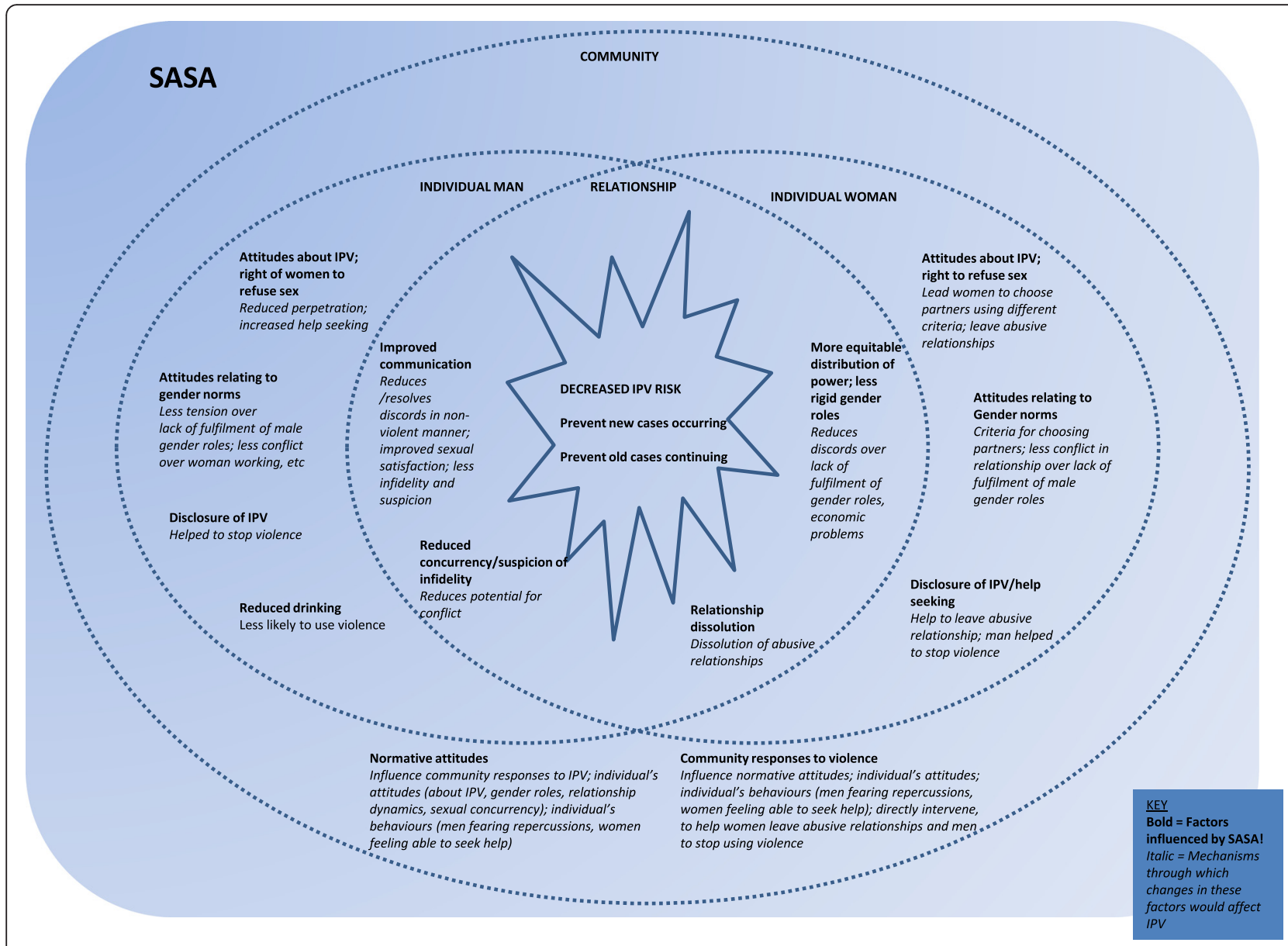

Fig. 2 Conceptual framework - pathways to reduced IPV risk

any one individual. For this reason, this paper does not attempt to 'model' a pathway by laying out a sequential chain of causation or proportioning out causality among the various factors. Instead, we attempt to outline which mediating factors played a role in reducing IPV.

\section{Outcome and mediator measures}

Table 2 presents the survey questions used to construct the IPV outcomes. Briefly, women's past year experience of IPV was measured using questions on experiences of specific violent acts by a partner (based on instruments used in the WHO Multi-country Study on Women's Health and Domestic Violence and the Uganda Demographic and Health Survey (DHS)) [35, 36]. Since baseline data from the SASA! study suggested that men are likely to underreport perpetration of such acts [37], and indeed male disclosure of IPV was extremely low in the follow-up survey especially in intervention communities, we used an alternative method to measure men's past year perpetration of IPV. We instead used violence data from cards that respondents were asked to fill out anonymously and place in a sealed envelope at the end of the interview. Details of the questions used to measure potential mediator variables are also presented in Table 2.

\section{Statistical analysis}

Intervention impacts on women's past year experience and men's past year perpetration of physical IPV were estimated using an adjusted cluster-level ITT analysis controlling for site pair, age, marital status and baseline EA-level prevalence of the outcome (as per the primary trial analysis) [27]. We explored the role of potential mediators using a three stage approach. We first used the same adjusted cluster-level ITT analysis method to estimate intervention impact on the intermediate outcomes identified in our conceptual framework. The analysis was performed separately for women and men. Individual- and relationship-level outcomes were binary, with adjusted risk ratios used as the measure of intervention impact. Community-level outcomes were continuous measures (enumeration area-level prevalence of each outcome), with intervention impact thus estimated using adjusted mean differences. 
Table 1 Measures of IPV and potential community-, relationship- and individual-level mediators of intervention effect on IPV

\begin{tabular}{|c|c|c|}
\hline Concept being measured & Indicator & Items in composite index \\
\hline \multicolumn{3}{|c|}{ IPV OUTCOMES (among women/men who have had a regular/casual partner in the past year) } \\
\hline Women's experience of IPV & $\begin{array}{l}\text { Women's past year experience of physical } \\
\text { IPV }\end{array}$ & $\begin{array}{l}\text { Reports that her partner/most recent partner has done at least } \\
\text { one of the following things to her in the past year: } \\
\text { - Slapped her or thrown something at her that could hurt her } \\
\text { - Pushed her or shoved her or pulled her hair } \\
\text { - Hit her with his fist or something else that could hurt her } \\
\text { - Kicked her, dragged her or beat her up } \\
\text { - Choked or burnt her on purpose } \\
\text { - Threatened to use or actually used a gun, knife or other weapon } \\
\text { against her } \\
\text { - Threatened to use or actually used a panga (stick) against her }\end{array}$ \\
\hline Men's perpetration of IPV & Men's past year perpetration of IPV & $\begin{array}{l}\text { Fills in anonymous card that 'yes' he has 'used violence on your } \\
\text { (partner) [most recent partner] in the last } 12 \text { months (last } \\
12 \text { months of your most recent relationship).' a }\end{array}$ \\
\hline
\end{tabular}

\section{MEDIATORS}

Community-level mediators (EA-level ${ }^{* *}$ aggregate prevalence)

Community responses to prevent violence

Norms around violence

Norms around women's control over sex
Okay for others in community to intervene if they know IPV is occurring

People who have witnessed/heard violence who have responded appropriately (among those who have seen or heard IPV in their community)

Acceptable for a man to use violence against his partner

Acceptable for a woman to refuse sex with her partner

Okay for a woman to ask her husband to use a condom
Among all respondents in EA, percentage who answers 'yes' to the question: 'If a husband beats up his wife, should others outside the couple intervene?'

Among respondents in EA who had seen or heard IPV happening in their community, percentage who reported that:

- 'Yes' they 'did something to try to help'

AND reported doing so with at least one of the following responses:

- Gathered other people in the community to help

- Knocked on the door to stop/distract the couple from fighting

- Separated the couple that was fighting

- Informed a community activist, ssenga, LC or police or any other authority

- Talked to the woman afterwards and told her to talk to a family member, friend, community activist, LC or ssenga or any other authority

- Talked to the woman afterwards and asked her how she wanted to be helped

- Talked to the man afterwards and told him that violence is never acceptable

- Talked to the man afterwards and told him to talk to a family member, friend, community activist, LC or ssenga or any other authority

- Talked to the man afterwards and tried to help him stop using violence

Among all respondents in EA, percentage who answer that 'yes', a man has good reason to hit his wife in at least one of the following scenarios:

- She disobeys him

- She answers back to him

- She disrespects his relatives

- He suspects that she is unfaithful

- He finds out she has been unfaithful

- She spends time gossiping with neighbours

- She neglects taking care of the children

- She doesn't complete her household work to his satisfaction

- She refuses to have sex with him

- She accuses him of infidelity

- She tells his secrets to others in the community

- He is angry with her

Among all respondents in EA, percentage who answer that 'yes' in their opinion it is acceptable if a married woman refuses to have sex with her husband if she doesn't feel like it.

Among all respondents in EA, percentage who answer that 'yes' it is acceptable for a married woman to ask her husband to use a condom. 
Table 1 Measures of IPV and potential community-, relationship- and individual-level mediators of intervention effect on IPV (Continued)

Broader gender norms

Others in community would respect a man who made decisions jointly with his wife

Man's role to decide if his wife can work

Relationship level mediators (for those partnered in past year)

Communication

Discuss things that happen in day

Discuss worries

Discuss what you both like during sex

Appreciate work partner does around house (where applicable)

Appreciate work partner does outside house (where applicable)

Power dynamics

Joint decision making

Man helps around house (among cohabiting couples)

Woman refused a job because husband doesn't want her to work

Woman participated in deciding how household finances spent (among cohabiting couples)

Additional sex partners

Concurrent partners (among nonpolygamous partnered respondents)

Male partner often suspicious that female partner is unfaithful

Relationship dissolution

Separated/divorced in past year (among those who have been married, lived together with someone as if married, or had a regular partner at some point in the last 12 months)

Individuals (for all respondents, separately for men and women)

Attitudes around violence

Acceptable for a man to use violence against his partner
Among all respondents in EA, percentage who answer that 'yes', if a husband told his friends that he makes decisions jointly with his wife, his friends would respect him.

Among all respondents in EA, percentage who answer that 'yes' they think it is a husband's role to decide whether or not his wife can work outside the home.

Answers 'yes' in the last 12 months they and their partner discuss things that happen to the respondent during the day, AND things that happen to their partner during the day.

Answers 'yes' in the last 12 months they and their partner discuss the respondent's worried or feelings.

Answers 'yes' that over the last 12 months they have openly asked their partner about what he/she likes during sex, AND that they have openly told their partner about what they themselves like during sex.

Answers 'many times' (versus 'none' or 'a few') to the question of how many times they have shown appreciation for the work their partner does inside the home.

Answers 'many times' (versus 'none' or 'a few') to the question of how many times they have shown appreciation for the work their partner does outside the home.

Answers that 'most of the time' or 'all of the time' in the last 12 months they have made decisions jointly with their partner on important issues, such as where they stay/live or what school the children attend

Answers that 'yes' in the last 12 months the male partner/male respondent has regularly helped with any of the housework.

Answer that 'yes' in the last 12 months the female respondent/ female partner has given up or refused a job for money outside the home because her partner did not want her to work.

Female respondent answers that 'yes' in the last 12 months she has participated in deciding how the family finances were spent.Male respondent answers that 'no' in the last 12 months he hasn't made all decisions regarding how the family finances were spent independent of his wife.

Answers that 'yes' they have had a sexual relationship with any other person in the last 12 months while being with their partner.

Reports that 'yes' in the last 12 months the male partner/male respondent has often been suspicious that the female respondent/female partner is unfaithful.

Among those who have been married or in a relationship at some point in the past year, those who report being currently 'separated', 'divorced' or 'single'.

Answers 'yes', a man has good reason to hit his wife in at least one of the following scenarios:

- She disobeys him

- She answers back to him

- She disrespects his relatives

- He suspects that she is unfaithful

- He finds out she has been unfaithful

- She spends time gossiping with neighbours

- She neglects taking care of the children

- She doesn't complete her household work to his satisfaction

- She refuses to have sex with him

- She accuses him of infidelity 
Table 1 Measures of IPV and potential community-, relationship- and individual-level mediators of intervention effect on IPV (Continued)

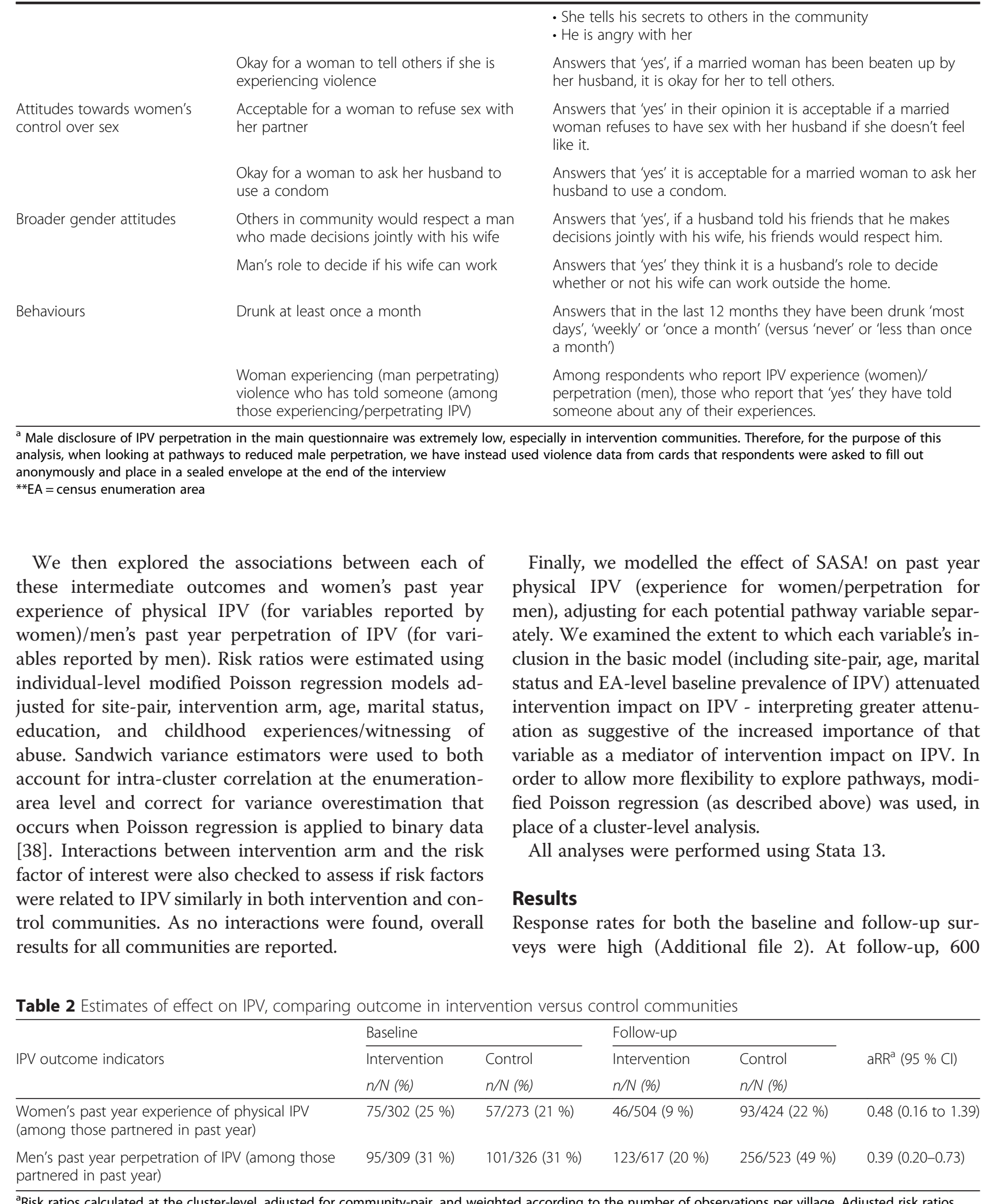

${ }^{a}$ Risk ratios calculated at the cluster-level, adjusted for community-pair, and weighted according to the number of observations per village. Adjusted risk ratios generated on the basis of expected number of events from a logistic regression model on individual data with independent variables including age, marital status and EA-level summary baseline measure of IPV 
women and 768 men were successfully interviewed in intervention communities (99\%), and 530 women and 634 men in control communities (98\%). At both timepoints there were high levels of comparability between intervention and control communities with respect to socio-demographic data (see Additional file 3 for descriptive data on the study sites and survey respondents). Prior to intervention implementation, intervention and control communities were also similar with respect to levels of IPV and the mediators for which baseline data were available (see Tables 2, 3 and 4) (although women in intervention communities were slightly more likely to report participating in deciding how household finances were spent).

As reported in the main trial paper, the relative risk of past year experience of physical IPV among women was $52 \%$ lower in intervention communities compared to control communities at follow-up (aRR 0.48, $95 \%$ CI $0.16-1.39$ ) [27]. Relative risk of men's past year perpetration of IPV (anonymously reported) was $61 \%$ lower in intervention communities compared to control communities (aRR 0.39, 95 \% CI 0.20-0.73).

\section{Which mediating factors played a role in reducing IPV?}

Intervention impacts on potential mediators are presented in Tables 3 (women) and 4 (men), and the relationships between these mediators and IPV in Table 5 . Table 6 shows the impact of SASA! on IPV experience (women)/perpetration (men), after adjustment for potential mediators.

\section{Community-level mediators}

Higher proportions of both men and women in SASA! communities compared to control communities reported responding appropriately if they had seen or heard IPV occurring in the past year. However, improved community response only appeared to be associated (non-significantly) with reduced risk of perpetration of IPV among men, not experience of IPV among women. In line with this, only among men was there was a slight attenuation of intervention effect on IPV when community response was included in the model (13\% reduction in effect size). The same picture was true for community attitudes towards the acceptability of intervening in cases of abuse - the mediating effect (this time stronger) only seen in relation to men's perpetration of IPV (38\% reduction in effect size), not women's experience.

SASA! was associated with a reduction in communitylevel acceptance of men using violence against their partners, a factor which in turn is associated with a lower risk of both IPV experience among women and IPV perpetration among men. Reduced acceptance of IPV at the community-level appears to have been a very important mediator of intervention impact on IPV among both women and men - inclusion of community attitudes towards violence in the model led to a $70 \%$ reduction in effect size for women's experience of IPV, and almost total attenuation of effect for men's perpetration.

SASA! communities were also more accepting than control communities of a woman's right both to refuse sex and to ask her husband to use a condom. The latter was more strongly related to reduced IPV risk, especially among women, and was also the more important mediator of intervention effect on IPV. There was a $32 \%$ reduction in effect size for women, and a $20 \%$ reduction in effect size for men, after acceptability of requesting condom use was included in the model.

SASA! led to increased community acceptance of joint decision making between partners, and decreased acceptance that it is a man's role to decide whether or not his wife can work. Both appear to be potential mediators of intervention impact on IPV, with the strongest attenuation of intervention impact seen in relation to community rejection of the notion that it is a man's role to decide if his wife can work ( $46 \%$ reduction in effect size for women; $67 \%$ reduction in effect size for men).

\section{Relationship-level mediators}

SASA! was associated with better communication between partners, as reported by both men and women (discussing things that happen to them both in the day, discussing worries, discussing what they both like during sex, and showing appreciation for work their partner does around the house). All of these indicators were in turn significantly associated with reduced IPV experience among women, though only appreciation of a partner's work was significantly associated with IPV perpetration among men. Improved communication appears to play a more important mediating role in intervention effect on IPV experience among women than it does in relation to IPV perpetration among men. The largest attenuation of effect among women was seen when discussion of what both partners like during sex was included in the model (16\% reduction).

Men and women in SASA! communities were also more likely to be in relationships characterised by more progressive power dynamics (more joint decision-making, the man helping around the house, the woman not made to refuse a job because her husband didn't want her to work, and the woman participating in deciding how household finances are spent). Indicators of greater equality within the relationship were significantly associated with reduced risk of IPV experience among women, and reduced perpetration among men. However, they emerged as only moderate mediators of intervention effect on IPV - the strongest attenuation of effect in women seen when joint decision-making was included in the model $(14 \%$ reduction in effect size), and the strongest in men when the 
Table 3 Estimates of intervention effect on potential mediators among women, comparing outcome in intervention versus control communities

\begin{tabular}{|c|c|c|c|c|c|}
\hline \multirow[b]{3}{*}{ COMMUNITY LEVEL ${ }^{c}$} & \multicolumn{2}{|l|}{ Baseline $^{a}$} & \multicolumn{2}{|l|}{ Follow-up } & \multirow[b]{2}{*}{$\mathrm{aRR}^{\mathrm{b}}(95 \% \mathrm{Cl})$} \\
\hline & Intervention & Control & Intervention & Control & \\
\hline & $\begin{array}{l}\text { EA-level mean risk } \\
\%(s d) n=16\end{array}$ & $\begin{array}{l}\text { EA-level mean risk } \\
\%(s d) n=16\end{array}$ & $\begin{array}{l}\text { EA-level mean risk } \\
\%(s d) n=23\end{array}$ & $\begin{array}{l}\text { EA-level mean risk } \\
\%(s d) n=24\end{array}$ & $\begin{array}{l}\text { Mean difference } \\
(95 \% \mathrm{Cl})\end{array}$ \\
\hline \multicolumn{6}{|l|}{ Community responses to prevent violence: } \\
\hline $\begin{array}{l}\text { Okay for others in community to intervene if } \\
\text { they know IPV is occurring }\end{array}$ & - & - & $79.2(7.1)$ & $58.7(6.5)$ & $20.3(10.2-30.4)$ \\
\hline $\begin{array}{l}\text { People who have witnessed/heard violence } \\
\text { who have responded appropriately }\end{array}$ & - & - & $47.2(16.3)$ & $29.8(13.6)$ & $13.0(-14.6-40.6)$ \\
\hline \multicolumn{6}{|l|}{ Norms around violence: } \\
\hline $\begin{array}{l}\text { Acceptable for a man to use violence against } \\
\text { his partner }\end{array}$ & $57.0(15.3)$ & $59.1(15.5)$ & $28.1(6.7)$ & $51.1(12.6)$ & $-26.7(-49.6--3.7)$ \\
\hline \multicolumn{6}{|l|}{ Norms around women's control over sex: } \\
\hline $\begin{array}{l}\text { Acceptable for a woman to refuse sex with } \\
\text { her partner }\end{array}$ & $40.4(14.7)$ & $35.3(15.1)$ & $91.3(3.2)$ & $74.7(10.3)$ & $18.4(6.0-30.9)$ \\
\hline $\begin{array}{l}\text { Okay for a woman to ask her husband to use } \\
\text { a condom }\end{array}$ & - & - & $78.5(3.2)$ & $59.2(7.3)$ & $20.4(13.5-27.4)$ \\
\hline \multicolumn{6}{|l|}{ Broader gender norms: } \\
\hline $\begin{array}{l}\text { Others in community would respect a man } \\
\text { who made decisions jointly with his wife }\end{array}$ & - & - & $75.2(0.5)$ & $57.2(16.6)$ & $22.8(-2.7-48.3)$ \\
\hline Man's role to decide if his wife can work & - & - & $39.3(2.3)$ & $58.6(9.9)$ & $-21.9(-36.9--7.0)$ \\
\hline RELATIONSHIP LEVEL (PARTNERED IN PAST YEAR) & $n / N(\%)$ & $n / N(\%)$ & $n / N(\%)$ & $n / N(\%)$ & $\operatorname{aRR}(95 \% \mathrm{Cl})$ \\
\hline \multicolumn{6}{|l|}{ Communication: } \\
\hline Discuss things that happen in day & 243/605 (80 \%) & $232 / 274(85 \%)$ & 402/482 (83\%) & 269/398 (68 \%) & $1.23(1.01-1.48)$ \\
\hline Discuss worries & 255/305 (84 \%) & 231/274 (84 \%) & 433/482 (90 \%) & 295/398 (74 \%) & $1.21(1.02-1.44)$ \\
\hline Discuss what you both like during sex & - & - & $321 / 481(67 \%)$ & 183/398 (46 \%) & $1.49(0.91-2.43)$ \\
\hline Appreciate work partner does around house & - & - & $269 / 397(68 \%)$ & 155/303 (51 \%) & $1.27(1.08-1.50)$ \\
\hline Appreciate work partner does outside house & - & - & $346 / 410$ (86 \%) & 244/308 (79 \%) & $1.08(0.97-1.19)$ \\
\hline \multicolumn{6}{|l|}{ Power dynamics: } \\
\hline Joint decision making & $219 / 266(82 \%)$ & 205/246 (83 \%) & $279 / 421(66 \%)$ & $154 / 332(46 \%)$ & $1.42(1.14-1.76)$ \\
\hline Man helps around house & 156/292 (53 \%) & 159/272 (58 \%) & 285/392 (73 \%) & $164 / 299(55 \%)$ & $1.33(0.94-1.88)$ \\
\hline $\begin{array}{l}\text { Woman refused a job because husband doesn't } \\
\text { want her to work }\end{array}$ & $76 / 300(25 \%)$ & $52 / 273(19 \%)$ & $54 / 454(12 \%)$ & 65/376 (17\%) & $0.78(0.15-4.10)$ \\
\hline Woman participated in deciding how household & $216 / 297(73 \%)^{*}$ & $169 / 272(62 \%)^{*}$ & $321 / 406$ (79 \%) & 217/313 (69\%) & $1.12(1.01-1.24)$ \\
\hline
\end{tabular}


Table 3 Estimates of intervention effect on potential mediators among women, comparing outcome in intervention versus control communities (Continued)

\begin{tabular}{|c|c|c|c|c|c|}
\hline \multicolumn{6}{|l|}{ Additional sex partners: } \\
\hline Concurrent partners & 18/247 (7 \%) & $8 / 215(4 \%)$ & $25 / 429(6 \%)$ & 20/341 (6 \%) & $1.25(0.37-4.22)$ \\
\hline $\begin{array}{l}\text { Male partner often suspicious that female partner } \\
\text { is unfaithful }\end{array}$ & - & - & 68/504 (13\%) & 98/425 (23 \%) & $0.65(0.24-1.73)$ \\
\hline \multicolumn{6}{|l|}{ Relationship dissolution: } \\
\hline Separated/divorced in past year & 8/299 (3 \%) & 3/264 (1 \%) & 9/486 (2 \%) & $17 / 401(4 \%)$ & $0.44(0.08-2.52)$ \\
\hline \multicolumn{6}{|l|}{ INDIVIDUALS (PARTNERED IN PAST YEAR) } \\
\hline \multicolumn{6}{|l|}{ Attitudes around violence: } \\
\hline $\begin{array}{l}\text { Acceptable for a man to use violence against } \\
\text { his partner }\end{array}$ & $181 / 304(60 \%)$ & 166/274 (61 \%) & 168/504 (33 \%) & $260 / 426(61 \%)$ & $0.56(0.38-0.82)$ \\
\hline $\begin{array}{l}\text { Okay for a woman to tell others if she is } \\
\text { experiencing violence }\end{array}$ & - & - & 409/504 (81 \%) & $241 / 427(56 \%)$ & $1.45(1.22-1.72)$ \\
\hline \multicolumn{6}{|l|}{ Attitudes towards women's control over sex: } \\
\hline $\begin{array}{l}\text { Acceptable for a woman to refuse sex with } \\
\text { her partner }\end{array}$ & $124 / 605(41 \%)$ & 95/274 (35 \%) & 465/504 (92\%) & $305 / 427(71 \%)$ & $1.30(1.03-1.65)$ \\
\hline $\begin{array}{l}\text { Okay for a woman to ask her husband to } \\
\text { use a condom }\end{array}$ & - & - & $401 / 504(80 \%)$ & $242 / 427(57 \%)$ & $1.41(1.18-1.69)$ \\
\hline \multicolumn{6}{|l|}{ Broader gender attitudes: } \\
\hline $\begin{array}{l}\text { Others in community would respect a man } \\
\text { who made decisions jointly with his wife }\end{array}$ & - & - & $385 / 504(76 \%)$ & $227 / 427(53 \%)$ & $1.49(0.91-2.44)$ \\
\hline Man's role to decide if his wife can work & - & - & 226/504 (45 \%) & 288/427 (67 \%) & $0.67(0.54-0.81)$ \\
\hline \multicolumn{6}{|l|}{ Behaviours: } \\
\hline Drunk at least once a month & - & - & 67/502 (13 \%) & $56 / 422(13 \%)$ & $0.98(0.56-1.70)$ \\
\hline $\begin{array}{l}\text { Woman experiencing (man perpetrating) } \\
\text { violence who has told someone }\end{array}$ & 78/132 (59 \%) & $54 / 112(48 \%)$ & 184/271 (68 \%) & 170/301 (56 \%) & $1.22(0.81-1.85)$ \\
\hline
\end{tabular}

${ }^{a}$ Question wording/item construction changed between baseline and follow-up to improve face validity - those baseline measures closest to the follow-up outcomes are presented here to assess underlying

intervention/control community comparability, but baseline/follow-up comparisons are not possible

${ }^{b}$ Risk ratios calculated at the cluster-level, adjusted for community-pair, and weighted according to the number of observations per village. Adjusted risk ratios generated on the basis of expected number of events

from a logistic regression model on individual data with independent variables including age and marital status

$c$ Mean number of respondents per $E A=28.0$ (range $18-35$ )
com

${ }^{*} x^{2}$-value $<0.005$ 
Table 4 Estimates of intervention effect on potential mediators among men, comparing outcome in intervention versus control communities

\begin{tabular}{|c|c|c|c|c|c|}
\hline \multirow[b]{3}{*}{ COMMUNITY LEVEL' } & \multicolumn{2}{|l|}{ Baseline } & \multicolumn{2}{|l|}{ Follow-up } & \multirow[b]{2}{*}{$\operatorname{aRR}^{\mathrm{a}}(95 \% \mathrm{Cl})$} \\
\hline & Intervention & Control & Intervention & Control & \\
\hline & $\begin{array}{l}\text { EA-level mean risk } \\
\%(s d) n=16\end{array}$ & $\begin{array}{l}\text { EA-level mean risk } \\
\%(s d) n=16\end{array}$ & $\begin{array}{l}\text { Mean difference } \\
(95 \% \mathrm{Cl})\end{array}$ & $\begin{array}{l}\text { EA-level mean risk } \\
\%(s d) n=24\end{array}$ & $\begin{array}{l}\text { Mean difference } \\
(95 \% \mathrm{Cl})\end{array}$ \\
\hline \multicolumn{6}{|l|}{ Community responses to prevent violence: } \\
\hline $\begin{array}{l}\text { Okay for others in community to intervene if they know } \\
\text { IPV is occurring }\end{array}$ & - & - & $92.5(6.6)$ & $42.8(11.9)$ & $47.6(21.9-73.3)$ \\
\hline $\begin{array}{l}\text { People who have witnessed/heard violence who have } \\
\text { responded appropriately }\end{array}$ & - & - & $62.8(15.1)$ & $26.1(10.7)$ & $33.3(-4.0-70.6)$ \\
\hline \multicolumn{6}{|l|}{ Norms around violence: } \\
\hline Acceptable for a man to use violence against his partner & $27.7(17.2)$ & $25.2(15.8)$ & $7.3(5.8)$ & $85.6(6.6)$ & $-75.5(-92.4--58.7)$ \\
\hline \multicolumn{6}{|l|}{ Norms around women's control over sex: } \\
\hline Acceptable for a woman to refuse sex with her partner & $53.5(18.3)$ & $55.6(14.0)$ & $97.5(2.6)$ & $75.4(12.9)$ & $23.0(1.0-45.0)$ \\
\hline Okay for a woman to ask her husband to use a condom & - & - & $88.6(12.2)$ & $43.6(8.8)$ & $41.8(17.8-65.8)$ \\
\hline \multicolumn{6}{|l|}{ Broader gender norms: } \\
\hline $\begin{array}{l}\text { Others in community would respect a man who made } \\
\text { decisions jointly with his wife }\end{array}$ & - & - & $88.9(10.5)$ & $38.9(10.9)$ & $48.3(29.7-66.9)$ \\
\hline Man's role to decide if his wife can work & - & - & $14.8(10.6)$ & $83.6(5.4)$ & $-67.0(-82.1--51.9)$ \\
\hline RELATIONSHIP LEVEL (PARTNERED IN PAST YEAR) & $n / N(\%)$ & $n / N(\%)$ & $n / N(\%)$ & $n / N(\%)$ & $\operatorname{aRR}(95 \% \mathrm{Cl})$ \\
\hline \multicolumn{6}{|l|}{ Communication: } \\
\hline Discuss things that happen in day & $275 / 313(88 \%)$ & 292/335 (87 \%) & $523 / 545(96 \%)$ & $318 / 434(73 \%)$ & $1.30(0.98-1.72)$ \\
\hline Discuss worries & 270/313 (86 \%) & 294/335 (88 \%) & $525 / 545(96 \%)$ & $326 / 434(75 \%)$ & $1.28(1.00-1.64)$ \\
\hline Discuss what you both like during sex & - & - & $481 / 544(88 \%)$ & 226/434 (52 \%) & $1.70(1.22-2.37)$ \\
\hline Appreciate work partner does around house & - & - & $385 / 409(94 \%)$ & $231 / 326(71 \%)$ & $1.32(1.04-1.69)$ \\
\hline Appreciate work partner does outside house & - & - & 228/283 (81 \%) & $128 / 244(52 \%)$ & $1.61(1.04-2.50)$ \\
\hline \multicolumn{6}{|l|}{ Power dynamics: } \\
\hline Joint decision making & 208/234 (89 \%) & 229/262 (87 \%) & 378/443 (85 \%) & 165/356 (46 \%) & $1.90(1.28-2.80)$ \\
\hline Man helps around house & 180/304 (59 \%) & $214 / 330(65 \%)$ & 396/411 (96 \%) & 229/326 (70 \%) & $1.42(0.98-2.05)$ \\
\hline $\begin{array}{l}\text { Woman refused a job because husband doesn't want } \\
\text { her to work }\end{array}$ & 26/313 (8 \%) & 26/335 (8 \%) & 27/506 (5 \%) & 123/410 (30 \%) & $0.12(0.02-0.89)$ \\
\hline $\begin{array}{l}\text { Woman participated in deciding how household } \\
\text { finances spent }\end{array}$ & $234 / 306(76 \%)^{*}$ & $271 / 327(83 \%)^{*}$ & $416 / 449$ (93 \%) & 218/345 (63 \%) & $1.48(1.11-1.97)$ \\
\hline \multicolumn{6}{|l|}{ Additional sex partners: } \\
\hline Concurrent partners & 109/270 (40 \%) & 105/284 (37 \%) & 139/508 (27 \%) & 177/397 (45 \%) & $0.60(0.37-0.97)$ \\
\hline $\begin{array}{l}\text { Male partner often suspicious that female partner } \\
\text { is unfaithful }\end{array}$ & - & - & 76/620 (12 \%) & 221/525 (42 \%) & $0.19(0.02-1.60)$ \\
\hline
\end{tabular}


Table 4 Estimates of intervention effect on potential mediators among men, comparing outcome in intervention versus control communities (Continued)

\section{Relationship dissolution:}

Separated/divorced in past year

$3 / 307(1 \%)$

$7 / 545(1 \%)$

$12 / 435(3 \%)$

$0.52(0.15-1.83)$

INDIVIDUALS (PARTNERED IN PAST YEAR)

Attitudes around violence:

Acceptable for a man to use violence against his partner

$81 / 313(26 \%)$

$83 / 335(25 \%)$

119/624 (19\%)

$454 / 525(86 \%)$

$0.14(0.02-1.11)$

Okay for a woman to tell others if she is experiencing

$-$

Attitudes towards women's control over sex:

Acceptable for a woman to refuse sex with her partner

Okay for a woman to ask her husband to use a condom $-$

Broader gender attitudes:

Others in community would respect a man who made decisions jointly with his wife

Man's role to decide if his wife can work

Behaviours:

Woman experiencing (man perpetrating) violence who has told someone

$-$

608/624 (97\%)

400/525 (76 \%)

$1.30(0.96-1.78)$

$536 / 624(86 \%)$

245/525 (47\%)

$1.86(1.28-2.70)$

$-$

$541 / 624$ (87 \%)

202/525 (38 \%)

$2.27(1.53-3.36)$

192/624 (31\%)

448/525 (85\%)

$0.27(0.06-1.25)$

92/311 (30\%)

$110 / 329(33 \%)$

162/619 (26\%)

200/525 (38 \%)

$0.69(0.38-1.27)$

39/105 (37\%)

$50 / 116(43 \%)$

$101 / 181(56 \%)$

$172 / 452(38 \%)$

$1.50(0.80-2.83)$

aRisk ratios calculated at the cluster-level, adjusted for community-pair, and weighted according to the number of observations per village. Adjusted risk ratios generated on the basis of expected number of events from a logistic regression model on individual data with independent variables including age and marital status

${ }^{b}$ Mean number of respondents per $E A=28.0$ (range $18-35$ )

${ }^{*} x^{2} p$-value $<0.005$ 
Table 5 Associations between potential mediators and past year experience (women)/perpetration (men) of physical IPV among respondents partnered in past year

\begin{tabular}{|c|c|c|}
\hline & $\begin{array}{l}\text { Women - aRR }(95 \% \mathrm{Cl}) \text { for past } \\
\text { year experience of IPV }\end{array}$ & $\begin{array}{l}\text { Men - aRR }(95 \% \mathrm{Cl}) \text { for past } \\
\text { year perpetration of IPV }\end{array}$ \\
\hline COMMUNITY LEVEL & $\begin{array}{l}\text { aRR of IPV for every } 10 \% \text { change in } \\
\text { community-prevalence of mediator }\end{array}$ & $\begin{array}{l}\text { aRR of IPV for every } 10 \% \text { change in } \\
\text { community-prevalence of mediator }\end{array}$ \\
\hline \multicolumn{3}{|l|}{ Community responses to prevent violence: } \\
\hline $\begin{array}{l}\text { Okay for others in community to intervene if they know } \\
\text { IPV is occurring }\end{array}$ & $0.94(0.79-1.13)$ & $0.88(0.74-1.04)$ \\
\hline $\begin{array}{l}\text { People who have witnessed/heard violence who have } \\
\text { responded appropriately }\end{array}$ & $0.98(0.87-1.10)$ & $0.91(0.80-1.04)$ \\
\hline \multicolumn{3}{|l|}{ Norms around violence: } \\
\hline Acceptable for a man to use violence against his partner & $1.35(1.18-1.54)$ & $1.18(0.99-1.40)$ \\
\hline \multicolumn{3}{|l|}{ Norms around women's control over sex: } \\
\hline Acceptable for a woman to refuse sex with her partner & $0.85(0.68-1.06)$ & $1.13(0.90-1.43)$ \\
\hline Okay for a woman to ask her husband to use a condom & $0.76(0.61-0.95)$ & $0.90(0.74-1.09)$ \\
\hline \multicolumn{3}{|l|}{ Broader gender norms: } \\
\hline $\begin{array}{l}\text { Others in community would respect a man who made } \\
\text { decisions jointly with his wife }\end{array}$ & $0.79(0.67-0.94)$ & $0.91(0.79-1.06)$ \\
\hline Man's role to decide if his wife can work & $1.34(1.17-1.54)$ & $1.16(1.00-1.35)$ \\
\hline RELATIONSHIP LEVEL (PARTNERED IN PAST YEAR) & $\begin{array}{l}\text { aRR of IPV in individuals with } \\
\text { versus without mediator }\end{array}$ & $\begin{array}{l}\text { aRR of IPV in individuals with } \\
\text { versus without mediator }\end{array}$ \\
\hline \multicolumn{3}{|l|}{ Communication: } \\
\hline Discuss things that happen in day & $0.36(0.23-0.56)$ & $0.99(0.58-1.70)$ \\
\hline Discuss worries & $0.31(0.18-0.54)$ & $0.95(0.63-1.43)$ \\
\hline Discuss what you both like during sex & $0.42(0.28-0.61)$ & $0.67(0.41-1.08)$ \\
\hline Appreciate work partner does around house & $0.44(0.28-0.69)$ & $0.56(0.35-0.90)$ \\
\hline Appreciate work partner does outside house & $0.46(0.27-0.80)$ & $0.53(0.34-0.80)$ \\
\hline \multicolumn{3}{|l|}{ Power dynamics: } \\
\hline Joint decision making & $0.27(0.16-0.47)$ & $0.61(0.39-0.96)$ \\
\hline Man helps around house & $0.63(0.39-1.03)$ & $0.59(0.35-0.98)$ \\
\hline $\begin{array}{l}\text { Woman refused a job because husband doesn't want } \\
\text { her to work }\end{array}$ & $4.65(2.59-8.36)$ & $2.78(1.70-4.56)$ \\
\hline $\begin{array}{l}\text { Woman participated in deciding how household } \\
\text { finances spent }\end{array}$ & $0.38(0.25-0.58)$ & $0.84(0.58-1.23)$ \\
\hline \multicolumn{3}{|l|}{ Additional sex partners: } \\
\hline Concurrent partners & $1.93(0.78-4.77)$ & $2.79(2.00-3.90)$ \\
\hline $\begin{array}{l}\text { Male partner often suspicious that female partner } \\
\text { is unfaithful }\end{array}$ & $6.35(3.73-10.80)$ & $4.51(3.31-6.13)$ \\
\hline \multicolumn{3}{|l|}{ Relationship dissolution: } \\
\hline Separated/divorced in past year & $4.25(1.49-12.13)$ & $2.13(0.42-10.88)$ \\
\hline \multicolumn{3}{|l|}{ INDIVIDUALS (PARTNERED IN PAST YEAR) } \\
\hline \multicolumn{3}{|l|}{ Attitudes around violence: } \\
\hline $\begin{array}{l}\text { Acceptable for a man to use violence against } \\
\text { his partner }\end{array}$ & $2.45(1.65-3.66)$ & $2.17(1.43-3.28)$ \\
\hline $\begin{array}{l}\text { Okay for a woman to tell others if she is experiencing } \\
\text { violence }\end{array}$ & $0.73(0.49-1.11)$ & $0.52(0.32-0.85)$ \\
\hline \multicolumn{3}{|l|}{ Attitudes towards women's control over sex: } \\
\hline Acceptable for a woman to refuse sex with her partner & $0.46(0.30-0.70)$ & $0.92(0.55-1.56)$ \\
\hline Okay for a woman to ask her husband to use a condom & $0.51(0.34-0.76)$ & $0.85(0.60-1.19)$ \\
\hline
\end{tabular}


Table 5 Associations between potential mediators and past year experience (women)/perpetration (men) of physical IPV among respondents partnered in past year (Continued)

\begin{tabular}{|c|c|c|}
\hline \multicolumn{3}{|l|}{ Broader gender attitudes: } \\
\hline $\begin{array}{l}\text { Others in community would respect a man who made } \\
\text { decisions jointly with his wife }\end{array}$ & $0.39(0.24-0.63)$ & $0.60(0.43-0.83)$ \\
\hline Man's role to decide if his wife can work & $2.25(1.38-3.69)$ & $1.92(1.29-2.85)$ \\
\hline \multicolumn{3}{|l|}{ Behaviours: } \\
\hline Drunk at least once a month & $1.61(0.89-2.93)$ & $2.33(1.82-3.00)$ \\
\hline
\end{tabular}

${ }^{a}$ Risk ratios adjusted for site-pair, intervention arm, age, marital status, education and childhood experiences of abuse

indicator of his partner refusing a job was included in the model (11\% reduction in effect size).

Men in SASA! communities were less likely than their control counterparts to report having had concurrent sexual partners in the past year. While sexual concurrency by the man is statistically significantly associated with men's reported perpetration of IPV, it does not appear to be a mediator of intervention effect on perpetration of IPV.

Women overall reported low levels of sexual concurrency, with no difference observed between intervention and control communities. However, both women and men in SASA! communities were less likely than their control counterparts to report that the man was often suspicious that his female partner was unfaithful. Reduced suspicion emerges as an important mediator of intervention effect on both women's IPV experience and men's IPV perpetration (18\% reduction in effect size for women; $22 \%$ reduction for men).

Relationship dissolution was slightly lower in SASA! communities than it was in control communities (though not significantly so), suggesting that SASA!'s effect on violence was not due to increased numbers of women leaving abusive relationships.

\section{Individual-level mediators - women}

Women in SASA! communities were less likely than their control counterparts to be accepting of a man's use of violence against his female partner (an attitude associated with increased risk of IPV), and more likely to think that it was okay for a woman to tell others if she was experiencing violence at the hands of her partner (an attitude associated with decreased risk of IPV). Of these two individual-level indicators, only attitudes accepting of violence emerged as a potentially important mediator of intervention effect on IPV, with its inclusion in the model resulting in a $16 \%$ reduction in effect size.

Women in SASA! communities were also more likely to believe that it was acceptable for a woman to refuse sex with her partner if she did not feel like it, and that it was okay for a woman to ask her husband to use a condom. Both of these were associated with a significant reduction in risk of IPV experience, and also emerged as potential mediators of intervention effect on IPV (attenuating effect size by 18 and $13 \%$ respectively when included in the model).

A higher proportion of women in SASA! communities reported believing that others in the community would respect a man who made decisions jointly with his wife (a perception associated with decreased IPV risk). Fewer were of the view that it is a man's role to decide if his wife can work (a view associated with increased IPV risk). Both indicators emerged as potential mediators of intervention effect on IPV, attenuating effect by 16 and $13 \%$ respectively.

SASA! did not impact on women's drinking behaviour.

\section{Individual-level mediators - men}

Men in SASA! communities were less likely than their control counterparts to be accepting of violence (an attitude associated with increased risk of perpetrating IPV), and more likely to believe that it was okay for a woman to tell others if she was experiencing violence (an attitude associated with decreased risk of perpetrating IPV). Both indicators were important mediators of intervention effect on perpetration of IPV, the former leading to a $42 \%$ reduction in effect size when included in the model, and the latter a $24 \%$ reduction.

Men in SASA! communities were also more likely to believe that it was acceptable for a woman to refuse sex with her partner, and that it was okay for a woman to ask her husband to use a condom. However, neither was associated with risk of IPV perpetration, and consequently neither was shown to mediate intervention effect on perpetration of IPV.

A higher proportion of men in SASA! communities believed that others in the community would respect a man who made decisions jointly with his wife (a perception associated with a decreased risk of perpetrating IPV). Fewer held the view that it is a man's role to decide if his wife can work (a view associated with an increased risk of perpetrating IPV). Both indicators emerged as potentially important mediators of intervention effect on IPV perpetration - their inclusion in the model attenuating intervention effect by 16 and $24 \%$ respectively. 
Table 6 SASA! impact on women's past year experience/men's past year perpetration of physical IPV, after adjustment for potential mediators

\begin{tabular}{|c|c|c|c|c|}
\hline \multirow[t]{2}{*}{ Mediator adjusted for: } & $\begin{array}{l}\text { aRR }^{\mathrm{a}}(95 \% \mathrm{CI}) \text { for SASA! impact on } \\
\text { women's experience of IPV }\end{array}$ & $\begin{array}{l}\% \text { change in aRR after } \\
\text { addition of mediator }\end{array}$ & $\begin{array}{l}\text { aRR }^{\mathrm{a}}(95 \% \mathrm{Cl}) \text { for SASA! impact } \\
\text { on men's perpetration of IPV }\end{array}$ & $\begin{array}{l}\text { \% change in aRR after } \\
\text { addition of mediator }\end{array}$ \\
\hline & \multicolumn{2}{|l|}{$n=875$} & \multicolumn{2}{|l|}{$n=1108$} \\
\hline Model without mediators & $0.44(0.30-0.64)$ & N/A & $0.45(0.30-0.70)$ & $\mathrm{N} / \mathrm{A}$ \\
\hline \multicolumn{5}{|l|}{ COMMUNITY LEVEL } \\
\hline \multicolumn{5}{|l|}{ Community responses to prevent violence: } \\
\hline $\begin{array}{l}\text { Okay for others in community to intervene if they know } \\
\text { IPV is occurring }\end{array}$ & $0.44(0.29-0.68)$ & $0 \%$ & $0.66(0.34-1.27)$ & $38 \%$ \\
\hline $\begin{array}{l}\text { People who have witnessed/heard violence who have } \\
\text { responded appropriately }\end{array}$ & $0.43(0.30-0.63)$ & $-2 \%$ & $0.52(0.31-86)$ & $13 \%$ \\
\hline \multicolumn{5}{|l|}{ Norms around violence: } \\
\hline Acceptable for a man to use violence against his partner & $0.83(0.50-1.38)$ & $70 \%$ & $0.97(0.40-2.39)$ & $95 \%$ \\
\hline \multicolumn{5}{|l|}{ Norms around women's control over sex: } \\
\hline Acceptable for a woman to refuse sex with her partner & $0.57(0.34-0.96)$ & $23 \%$ & $0.41(0.26-0.64)$ & $-7 \%$ \\
\hline Okay for a woman to ask her husband to use a condom & $0.62(0.39-0.99)$ & $32 \%$ & $0.56(0.30-1.02)$ & $20 \%$ \\
\hline \multicolumn{5}{|l|}{ Broader gender norms: } \\
\hline $\begin{array}{l}\text { Others in community would respect a man who made } \\
\text { decisions jointly with his wife }\end{array}$ & $0.64(0.40-1.01)$ & $36 \%$ & $0.58(0.34-1.00)$ & $24 \%$ \\
\hline Man's role to decide if his wife can work & $0.70(0.48-1.03)$ & $46 \%$ & $0.82(0.42-1.59)$ & $67 \%$ \\
\hline \multicolumn{5}{|l|}{ RELATIONSHIP LEVEL (PARTNERED IN PAST YEAR) } \\
\hline \multicolumn{5}{|l|}{ Communication: } \\
\hline Discuss things that happen in day & $0.51(0.35-0.74)$ & $13 \%$ & $0.46(0.30-0.69)$ & $2 \%$ \\
\hline Discuss worries & $0.51(0.36-0.73)$ & $13 \%$ & $0.47(0.31-0.70)$ & $4 \%$ \\
\hline Discuss what both like during sex & $0.53(0.36-0.77)$ & $16 \%$ & $0.49(0.32-0.75)$ & $7 \%$ \\
\hline Appreciate work partner does around house & $0.46(0.32-0.65)$ & $4 \%$ & $0.48(0.32-0.72)$ & $5 \%$ \\
\hline Appreciate work partner does outside house & $0.45(0.31-0.65)$ & $2 \%$ & $0.48(0.32-0.71)$ & $5 \%$ \\
\hline \multicolumn{5}{|l|}{ Power dynamics: } \\
\hline Joint decision making & $0.52(0.37-0.74)$ & $14 \%$ & $0.49(0.34-0.72)$ & $7 \%$ \\
\hline Man helps around house & $0.47(0.32-0.67)$ & $5 \%$ & $0.49(0.32-0.73)$ & $7 \%$ \\
\hline $\begin{array}{l}\text { Woman refused a job because husband doesn't want } \\
\text { her to work }\end{array}$ & $0.48(0.34-0.70)$ & $7 \%$ & $0.51(0.34-0.76)$ & $11 \%$ \\
\hline $\begin{array}{l}\text { Woman participated in deciding how household } \\
\text { finances spent }\end{array}$ & $0.47(0.34-0.66)$ & $5 \%$ & $0.47(0.32-0.70)$ & $4 \%$ \\
\hline \multicolumn{5}{|l|}{ Additional sex partners: } \\
\hline Concurrent partners & - & - & $0.49(0.34-0.73)$ & $7 \%$ \\
\hline Male partner often suspicious that female partner is unfaithful & $0.54(0.38-0.76)$ & $18 \%$ & $0.57(0.40-0.81)$ & $22 \%$ \\
\hline
\end{tabular}


Table 6 SASA! impact on women's past year experience/men's past year perpetration of physical IPV, after adjustment for potential mediators (Continued)

INDIVIDUALS (PARTNERED IN PAST YEAR)

Attitudes around violence:

Acceptable for a man to use violence against his partner

$0.53(0.36-0.80)$

$16 \%$

$4 \%$

$0.68(0.43-1.09)$

Okay for a woman to tell others if she is experiencing violence

$0.46(0.32-0.67)$

$0.57(0.37-0.90)$

$22 \%$

Attitudes towards women's control over sex

Acceptable for a woman to refuse sex with her partner

$0.54(0.37-0.77)$

$18 \%$

$0.48(0.31-0.73)$

$5 \%$

Okay for a woman to ask her husband to use a condom

$0.51(0.34-0.76)$

Broader gender attitudes:

Others in community would respect a man who made decisions

$0.53(0.36-0.78)$

$0.54(0.36-0.83)$

with his wife

$0.51(0.35-0.72)$

$0.58(0.37-0.90)$

$24 \%$ Behaviours:

$0.47(0.33-0.69)$

$4 \%$

${ }^{2}$ Adjusted risk ratios calculated using modified poisson regression with cluster robust standard errors, and adjusted for site-pair, age, marital status and EA-level baseline prevalence of IPV 
While a slight (though statistically non-significant) decrease in frequent drunkenness was observed among men in SASA! communities, and despite the fact that frequent drunkenness is strongly associated with increased risk of IPV perpetration, changes in drinking behaviour do not appear to have been mediators of intervention effect on perpetration of IPV.

\section{Discussion}

This analysis has identified a number of potentially important pathways through which SASA! worked to prevent physical IPV against women. Pathways include factors operating at the community-, relationship- and individual-level, and reinforce findings from qualitative research conducted with SASA! community members [34].

At the community-level, changes in normative attitudes, particularly those around the acceptability of violence and more progressive gender relations, appear to have played a hugely significant mediating role in preventing IPV. Reductions in the acceptability of violence explain most of the intervention effect seen in women and almost all of the effect seen in men. The extent of the mediating role of normative attitudes, especially among men, suggests peer pressure and a perceived threat of sanctions as potentially important mechanisms for preventing perpetration of IPV.

Community responses to IPV were observed to somewhat mediate the impact of SASA! on male perpetration of IPV, but not on female experience of IPV. It is plausible that community responses on the part of other men are more effective at producing fear of sanctions among men (and thereby discouraging perpetration) than other women's responses are at helping women out of abusive situations. There is also a possible two-way relationship between community response and individual risk of IPV. High rates of IPV within a community could motivate and prime community members to mount a better response to the violence, thereby causing us to underestimate the role of community response as a mediator in IPV reductions.

At the relationship-level, several indicators of improved communication and more equal power dynamics appear to play a moderate mediating role in intervention effect on IPV experience among women. Their mediating role was smaller in relation to men's perpetration. Potential mechanisms of mediation include reductions in stressful situations and miscommunications that might trigger relationship conflict and violence [34].

Interestingly, suspicion by the man that his female partner is unfaithful was the most important relationship-level mediator of intervention effect on both women's experience and men's perpetration of IPV. This suggests that efforts to reduce levels of suspicion within relationships - for example through encouraging improved communication, or challenging gender norms that make it unacceptable for a woman to refuse sex with her husband or seek work outside the home without arousing suspicion could form a potentially important part of violence prevention strategies.

At the individual-level, it is interesting to note that male attitudes towards the acceptability of IPV are much more important mediators of intervention effect on IPV perpetration, than female attitudes are in relation to IPV experience. This is in line with evidence from other studies [19], and is not surprising. While a man's attitudes can directly influence whether or not he uses violence, a woman's attitudes can impact on her own experiences of IPV only indirectly, through influencing her choice of partner or her motivation to leave an abusive partner - the latter reaction does not appear to have become more common in SASA! communities.

Among men, attitudes towards the acceptability of IPV appear to be more influential mediators of intervention effect than attitudes towards broader gender norms. This supports the idea that reductions in broad measures of gender inequality may not be sufficient in themselves to prevent violence, if specific attitudes towards the acceptability of violence against women are not also directly addressed and challenged. The finding that men's individual-level attitudes towards a woman's right to refuse sex do not appear to play a role in IPV reduction, also suggests that the issue of sexual coercion within a partnership might not always be strongly linked to use of physical violence.

This study has many strengths, not least that the data come from a cluster randomised trial which allows us to compare intervention and control communities and thus identify mediating factors that are associated with reductions in violence, not just prevalence of violence. Nevertheless, there are limitations to this analysis. As with other violence research studies, our analysis is of self-reported data which may be prone to respondent or recall bias. Another limitation is that the data are cross-sectional, meaning it is not possible to determine whether observed associations are causal and, if they are, what the direction of that causal association is. The randomised design and ITT analysis, along with baseline data showing intervention and control communities to be highly comparable prior to intervention implementation, lend support to the interpretation that SASA! positively impacted on the mediating variables. However, we cannot rule out a loop of causality in the latter end of the causal pathway, whereby the change in a mediator is brought about by a reduction in IPV rather than the reverse scenario. Prior to conducting any analysis, we laid out theoretically and empirically grounded plausible pathways of effect in a conceptual framework. Our analysis and interpretation thus reflects our a priori suppositions about causality and directions of effect, rather than definitively testing a causal pathway. 
Another likely source of endogeneity is that the role of each mediator may have been positively confounded by other variables not included in the model (including other potential mediators with which it is correlated). As already stated, due to the complex web of causation invoked by an intervention such as SASA!, involving a multitude of closely interrelated social phenomena, our analysis attempts to identify which types of mediators play a role in reducing IPV rather than producing precise estimates of the proportion of intervention effect that can be attributed to each. While it is possible that the role of certain mediators has been exaggerated, confounding is unlikely to wholly explain the large attenuations of effect observed when, for example, community level attitudes are included in the model of intervention effect on IPV.

A further constraint that we faced in the analysis is that, while we looked at pathways to both IPV experience (women) and IPV perpetration (men), our data did not pertain to men and women in the same relationships, nor living within the same immediate localities. We could not therefore directly explore the mediating influences of men's factors (including community norms among men) on women's experiences of IPV, or women's factors (including community norms among women) on men's perpetration of IPV. Nevertheless, the broad range of mediators included in the analysis still allows us to gain insights into diverse pathways through which the intervention may have brought about reductions in IPV.

Despite limitations, this study provides major new insights to the field of violence prevention research. One interesting finding is that attitudes are similarly related to IPV risk in both intervention and control communities. This suggests that SASA! has not only managed to change what people say they believe, but has changed attitudes in a meaningful way that relates to behaviours. Evidence that such change can occur over a relatively short period of programming offers validation to the approaches of interventions such as SASA! which aim to prevent violence through norm change.

Most importantly, the study sheds light on key pathways of effect that violence prevention interventions can and should exploit. At the relationship-level, an important insight is the role that reduced suspicion of infidelity within the relationship may play in mediating intervention effect on IPV. The finding that men's attitudes play more of a mediating role than women's attitudes points to the importance of working with both men and women, in contrast to approaches which work solely with women. Perhaps most noteworthy is the finding that communitylevel factors, in particular norms relating to the acceptability of a man's use of violence against his partner, are the major mediators of intervention effect on both female experience and male perpetration of IPV. They appear to play a more significant mediating role than changes at either the relationship- or individual-level. To our knowledge, such a finding has not been previously demonstrated in relation to a violence prevention intervention study. It highlights the imperative of addressing the underlying contexts in which IPV occurs, and lends strong support for the more widespread adoption of communitylevel approaches to preventing violence.

\section{Conclusion}

The SASA! study was the first CRT in sub-Saharan Africa to assess the community-level impact of a violence prevention programme. Results suggest not only that community-level violence prevention is possible over a relatively short time-frame, but that community-level norm change may in fact be the most effective means of achieving reductions in IPV risk. They also demonstrate the importance of working with both men and women to achieve reductions in IPV risk, with changes to individuallevel attitudes and relationship dynamics as reported by both men and women emerging as pathways through which violence was reduced. Overall, these findings have important implications for violence prevention programming - while programmes have often focused on changing attitudes among individual programme recipients, greater reductions in risk might be achieved by changing pervasive norms in the wider community. As testimony to its success, SASA! is currently being replicated in 14 countries - the core systematic approach to tackling the underlying community-level drivers of violence preserved amidst local adaptations to materials, activities, activity settings and key personnel. More research and investment is now urgently needed for the further development of community-level interventions to prevent violence, and to better understand and support their effective replication and scale-up.

\section{Availability of supporting data}

Data from the follow-up survey and limited data from the baseline survey can be requested from the London School of Hygiene and Tropical Medicine Data Compass: http://datacompass.lshtm.ac.uk/19/

\section{Additional files}

Additional file 1: Intervention logic model. Detailed description of intervention logic model. (PPT $238 \mathrm{~kb}$ )

Additional file 2: Trial profile. Diagram showing the flow of communities and participants through the trial. (PPTX $72 \mathrm{~kb}$ )

Additional file 3: Descriptive data on study sites and respondents. Descriptive data comparing intervention and control communities at baseline and follow-up. (DOCX $16 \mathrm{~kb}$ )

\section{Abbreviations}

aRR: adjusted risk ratio; CA: community activist (in the SASA! Intervention); CEDOVIP: Centre for Domestic Violence Prevention; Cl: confidence interval; 
CRT: cluster randomized trial; EA: enumeration area; IPV: intimate partner violence.

\section{Competing interests}

Lori Michau is co-Director of Raising Voices and designed the SASA! intervention. Janet Nakuti is the Monitoring and Evaluation Officer for Raising Voices. Tina Musuya is the Director of CEDOVIP and in charge of the implementation of the SASA! intervention being evaluated. They have played a central role in ensuring the appropriate conceptualisation and implementation of the evaluation, including the topics covered in the study questionnaire, the implementation of the fieldwork, and ensuring the provision of support to women requesting assistance. They have had no involvement in the randomisation of matched community pairs, no direct involvement in data collection for the CRT, and no involvement with the data analysis. They have input into the interpretation of the findings.

\section{Author's contributions}

CW, LM and TM are Principal Investigators on the study, responsible for the overall conceptualisation, design and management of the study. TA, KD and LK are social epidemiologists responsible for major aspects of study design, sampling, development of research instruments, interviewer training and supervision of the quantitative survey. JN has input to the development and implementation of monitoring and evaluation instruments, the development of the follow-up questionnaire, and interviewer training, as well as being involved in baseline data collection and data management, and implementation and supervision of the follow-up survey. NK is the social scientist leading the qualitative research and analysis as well as inputting into the development of the follow-up questionnaire, interviewer training and implementation and supervision of the follow-up survey. TA drafted the manuscript and conducted the statistical analysis for this paper. All authors have commented on and offered edits to the original draft, and all have read and approved the final version.

\section{Acknowledgements}

Many people, both within and outside these institutions, have helped to make this study possible. We would like to thank Irish Aid, the Sigrid Rausing Trust, 3ie (International Initiative for Impact Evaluations), an anonymous donor, AusAID and the Stephen Lewis Foundation, for providing funding for this research, and Irish Aid, American Jewish World Service, HIVOS, and the NoVo Foundation for supporting the implementation and monitoring of SASA! in the study communities. The analysis and writing of this article was supported by an anonymous donor and the STRIVE RPC, an international research consortium funded by the UK Department for International Development (DFID) to investigate structural drivers of HIV The views expressed are those of the authors alone.

Many thanks go to staff at Raising Voices and CEDOVIP, who have not only been responsible for the design and implementation of the SASA! intervention, but also tirelessly supported the research process, working with community leaders to gain consent for the study, participating in questionnaire design, training interviewers, conducting monitoring and evaluation activities and qualitative research as well as providing administrative support. Particularly, Winnie Amono, Gladys Rachiu, Clinton Okecha, Dipak Naker, Josephine Kamisya, Hope Turyasingura, Yvette Alal, Peter Wateya, Deus Kiwanuka, Denis Kizito Odok, Olive Nabisubi, Paul Buuzibwa, and Rose Muduwa. Staff at the Uganda Bureau of Statistics (UBOS) were invaluable in our preparations for the surveys, both providing administrative maps and helping to recruit trained mappers to conduct the mapping exercises. We would also like to thank Basil Wanzira and Mabel Luzze who led the data collection and data management for the baseline survey, and Julius Lwanyaaga, Barbrah Nanyunja, Barbara Athieno, Miriam Dhikusooka, Josephine Namatovu, Angella Beatrice Nalwanga, Edgar Karungi and Betty Katengeke who led the data collection and data management for the follow-up survey. Though there are too many to list here, many thanks go to all of the researchers and data entry staff who spent months collecting and organising the data. We are also grateful to the local advisory committee, including Jessica Nkuuhe, Dr. Consolata Kabonesa, Mubarak Mabuya, Helen Nviiri and Dr. Freddie Ssengooba, who offered valuable feedback and advice during the design and conceptualisation of the SASA! study. Among colleagues at the London School of Hygiene and Tropical Medicine, we would like to thank Dr James Hargreaves and colleagues at the Centre for Evaluation, and Professor Richard Hayes for advice on aspects of study design and statistical methods for cluster randomised trials. Thanks also to Dr Lori Heise for providing useful thoughts and references relating to the relationship between social norms and IPV.

We are extremely grateful also to the men and women who have been surveyed for the study, who graciously shared their time and stories with us. We would especially like to acknowledge all of the Raising Voices and CEDOVIP staff and community activists also, who work tirelessly to prevent violence in their communities. It is only through their hard work and commitment to transforming gender relationships and ending violence, that the impacts documented in this study have been achieved.

\section{Author details}

${ }^{1}$ Gender Violence and Health Centre, London School of Hygiene and Tropical Medicine, 15-17 Tavistock Place, London WC1H 9SH, UK. ${ }^{2}$ Raising Voices, 16 Tufnell Drive, Kamwokya, P.O Box 6770 Kampala, Uganda. ${ }^{3}$ Centre for Domestic Violence Prevention, 16 Tufnell Drive, Kamwokya, P.O Box 6770 Kampala, Uganda.

\section{Received: 15 September 2015 Accepted: 8 April 2016 \\ Published online: 16 April 2016}

\section{References}

1. Devries KM, Mak JY, Bacchus $\amalg$, Child JC, Falder G, Petzold M, et al. Intimate partner violence and incident depressive symptoms and suicide attempts: a systematic review of longitudinal studies. PLoS Med. 2013;10(5):e1001439.

2. Jewkes RK, Dunkle K, Nduna M, Shai N. Intimate partner violence, relationship power inequity, and incidence of HIV infection in young women in South Africa: a cohort study. Lancet. 2010;376(9734):41-8.

3. Zablotska IB, Gray RH, Koenig MA, Serwadda D, Nalugoda F, Kigozi G, et al. Alcohol use, intimate partner violence, sexual coercion and HIV among women aged 15-24 in Rakai, Uganda. AIDS Behav. 2009;13(2):225-33.

4. Kouyoumdjian FG, Calzavara LM, Bondy SJ, O'Campo P, Serwadda D, Nalugoda F, et al. Intimate partner violence is associated with incident HIV infection in women in Uganda. AIDS. 2013;27(8):1331-8.

5. Devries KM, Mak JY, Garcia-Moreno C, Petzold M, Child JC, Falder G, et al. Global health. The global prevalence of intimate partner violence against women. Science. 2013;340(6140):1527-8.

6. Heise LL. Violence against women: an integrated, ecological framework. Violence Against Women. 1998;4(3):262-90.

7. Heise L. What works to prevent partner violence? An evidence overview. London: STRIVE Research Consortium; 2011.

8. Heise L. Determinants of partner violence in Brazil and Peru: Exploring variation in individual and population level risk. London: London School of Hygiene and Tropical Medicine; 2011.

9. Heise L, Kotsadam A. Exploring cross-national and multi-level correlates of partner violence: an analysis of data from population-based surveys. Lancet Glob Health. 2015;3(6):332-40.

10. Uthman OA, Moradi T, Lawoko S. Are individual and community acceptance and witnessing of intimate partner violence related to its occurrence? Multilevel structural equation model. PLoS One. 2011;6(12):e27738.

11. Boyle MH, Georgiades K, Cullen J, Racine Y. Community influences on intimate partner violence in India: Women's education, attitudes towards mistreatment and standards of living. Soc Sci Med. 2009;69(5):691-7.

12. Koenig MA, Stephenson R, Ahmed S, Jejeebhoy SJ, Campbell J. Individual and contextual determinants of domestic violence in North India. Am J Public Health. 2006;96(1):132-8.

13. Levinson D. Family violence in cross-cultural perspective. Thousand Oaks (CA): Sage; 1989.

14. Koenig MA, Ahmed S, Hossain MB, Khorshed Alam Mozumder AB. Women's status and domestic violence in rural Bangladesh: individual- and community-level effects. Demography. 2003;40(2):269-88.

15. Ackerson LK, Kawachi I, Barbeau EM, Subramanian SV. Effects of individual and proximate educational context on intimate partner violence: a population-based study of women in India. Am J Public Health. 2008:98(3):507-14.

16. Gage AJ. Women's experience of intimate partner violence in Haiti. Soc Sci Med. 2005;61(2):343-64.

17. Counts D, Brown J, Campbell J. Sanctions and sanctuary: cultural perspectives on the beating of wives. Boulder (CO): Westview Press; 1992.

18. Abramsky T, Watts $\mathrm{CH}$, Garcia-Moreno C, Devries K, Kiss L, Ellsberg M, et al, What factors are associated with recent intimate partner violence? findings 
from the WHO multi-country study on women's health and domestic violence. BMC Public Health. 2011:11:109.

19. Hindin M, Kishor S, Ansara D. Intimate partner violence among couples in 10 DHS countries: Predictors and health outcomes. Calverton: Macro International Inc:; 2008.

20. Jewkes R. Intimate partner violence: causes and prevention. Lancet. 2002; 359(9315):1423-9.

21. Ellsberg M, Arango DJ, Morton M, Gennari F, Kiplesund S, Contreras M, et al. Prevention of violence against women and girls: what does the evidence say? Lancet. 2015;385(9977):1555-1566.

22. Pronyk PM, Hargreaves JR, Kim JC, Morison LA, Phetla G, Watts C, et al. Effect of a structural intervention for the prevention of intimate-partner violence and HIV in rural South Africa: a cluster randomised trial. Lancet. 2006;368(9551):1973-83.

23. Jewkes $\mathrm{R}$, Nduna $\mathrm{M}$, Levin J, Jama N, Dunkle K, Puren A, et al. Impact of stepping stones on incidence of HIV and HSV-2 and sexual behaviour in rural South Africa: cluster randomised controlled trial. BMJ. 2008:337:a506.

24. Hossain M, Zimmerman C, Kiss L, Abramsky T, Kone D, Bakayoko-Topolska $M$, et al. Working with men to prevent intimate partner violence in a conflict-affected setting: a pilot cluster randomized controlled trial in rural Cote d'Ivoire. BMC Public Health. 2014;14:339.

25. Usdin S, Scheepers E, Goldstein S, Japhet G. Achieving social change on gender-based violence: a report on the impact evaluation of Soul City's fourth series. Soc Sci Med. 2005;61(11):2434-45.

26. Solorzano I, Bank A, Pena R, Espinoza H, Ellsberg M, Pulerwitz J. Catalyzing personal and social change around gender, sexuality, and HIV: Impact evaluation of Puntos de Encuentro's communication strategy in Nicaragua. Washington DC: Population Council; 2008.

27. Abramsky T, Devries KM, Kiss L, Nakuti J, Kyegombe N, Starmann E, et al. Findings from the SASA! Study: a cluster randomized controlled trial to assess the impact of a community mobilization intervention to prevent violence against women and educe HIV risk in Kampala, Uganda. BMC Med. 2014:12:122.

28. Wagman JA, Gray RH, Campbell JC, Thoma M, Ndyanabo A, Ssekasanvu J, et al. Effectiveness of an integrated intimate partner violence and HIV prevention intervention in Rakai, Uganda: analysis of an intervention in an existing cluster randomised cohort. Lancet Glob Health. 2015:3(1):e23-33.

29. Uganda Ministry of Health and ICF International. Uganda AIDS Indicator Survey 2011: Key Findings. Calverton, Maryland, USA: 2012.

30. Uganda Bureau of Statistics and ICF International Inc. Uganda Demographic and Health Survey 2011. Calverton: Measure DHS, ICF International; 2012.

31. Michau L. The SASA ! Activist Kit for Preventing Violence against Women and HIV. Kampala: Raising Voices; 2008.

32. Prochaska JO, Diclemente CC, Norcross JC. In search of How people change - applications to addictive behaviors. Am Psychol. 1992;47(9):1102-14.

33. Abramsky T, Devries K, Kiss L, Francisco L, Nakuti J, Musuya T, et al. A community mobilisation intervention to prevent violence against women and reduce HIV/AIDS risk in Kampala, Uganda (the SASA! Study): study protocol for a cluster randomised controlled trial. Trials. 2012;13:96.

34. Kyegombe N, Starmann E, Devries KM, Michau L, Nakuti J, Musuya T, et al. 'SASA! is the medicine that treats violence'. Qualitative findings on how a community mobilisation intervention to prevent violence against women created change in Kampala, Uganda. Glob Health Action. 2014;7:25082

35. Garcia-Moreno CJH, Ellsberg M, Heise L, Watts C. WHO multi-country study on womens health an domestic violence against women. Geneva: WHO; 2005 .

36. Uganda Bureau of Statistics and Macro International Inc. Uganda demographic and health survey 2006. Calverton: UBOS and Macro International Inc:; 2007.

37. Abramsky T, Francisco L, Kiss L, Michau L, Musuya T, Kaye D, et al. SASA! baseline report. Kampala: Raising Voices, London School of Hygiene and Tropical Medicine; 2010.

38. Zou GY, Donner A. Extension of the modified Poisson regression model to prospective studies with correlated binary data. Stat Methods Med Res. 2013;22(6):661-70

\section{Submit your next manuscript to BioMed Central and we will help you at every step:}

- We accept pre-submission inquiries

- Our selector tool helps you to find the most relevant journal

- We provide round the clock customer support

- Convenient online submission

- Thorough peer review

- Inclusion in PubMed and all major indexing services

- Maximum visibility for your research

Submit your manuscript at www.biomedcentral.com/submit
Biomed Central 